\title{
Impact of Working Memory Training Targeting the Central Executive on Kindergarteners' Numerical Skills
}

\author{
Nastasya Honoré ${ }^{1}$, Marie-Pascale Noël ${ }^{1}$ \\ ${ }^{1}$ Psychological Sciences Research Institute, Université Catholique de Louvain, Belgium \\ Correspondence: Nastasya Honoré, Pscyhological Sciences Research Institute, Université Catholique de Louvain, 10 \\ Place Cardinal Mercier, 1348 Louvain-la-Neuve, Belgium.
}

Received: January 10, 2017

doi:10.11114/jets.v5i5.2131

\author{
Accepted: March 1, $2017 \quad$ Online Published: April 18, 2017 \\ URL: https://doi.org/10.11114/jets.v5i5.2131
}

\begin{abstract}
Working memory capacities are associated with mathematical development. Many studies have tried to improve working memory abilities through training. Furthermore, the central executive has been shown to be the component of working memory, which is the most strongly related to numerical and arithmetical skills. Therefore, we developed a training program that specifically targeted the central executive to examine the possible impact on kindergarteners' working memory and numerical abilities. Thirty-four 5-6 year olds were randomly assigned to the experimental or the control conditions. Both groups received 1630 -minute sessions of their respective training program. The experimental group was trained with games tapping the central executive and the control group received a vocabulary-learning program. The results showed an immediate training effect on one central executive task and an effect of training appeared on another central executive task at follow-up, 6 months later. However, no impact was observed on numerical and arithmetical skills.
\end{abstract}

Keywords: working memory, central executive training, numerical development, arithmetic, kindergarteners

\section{Introduction}

Numerical development relies on several domain-general cognitive factors, such as intelligence (Geary, Hamson, \& Hoard, 2000; Passolunghi \& Lanfranchi, 2012; Passolunghi, Mammarella, \& Altoe, 2008), attention (Fuchs et al., 2005; Fuchs et al., 2006), inhibition (D'Amico \& Passolunghi, 2009; Espy et al., 2004; St Clair-Thompson \& Gathercole, 2006), processing speed (Bull \& Johnston, 1997; D'Amico \& Passolunghi, 2009; Fuchs et al., 2006; Geary, Hoard, Byrd-Craven, Nugent, \& Numtee, 2007; Passolunghi \& Lanfranchi, 2012), phonological abilities (Fuchs et al., 2006; Geary et al., 2000; Hecht, Torgesen, Wagner, \& Rashotte, 2001) or working memory (e.g. Bull, Johnston, \& Roy, 1999; De Smedt et al., 2009; DeStefano \& Lefevre, 2004; Fuchs et al., 2005; Gathercole \& Pickering, 2000b; Passolunghi, Cornoldi, \& De Liberto, 1999; Passolunghi \& Lanfranchi, 2012; Passolunghi et al., 2008; Passolunghi \& Siegel, 2001, 2004; Passolunghi, Vercelloni, \& Schadee, 2007; St Clair-Thompson \& Gathercole, 2006).

The present study took a particular interest in the link between numerical abilities and working memory. Several authors have shown that poor working memory capacities are associated with difficulties in early numeracy (Attout, Noël, \& Majerus, 2014; Gersten, Jordan, \& Flojo, 2005; Noël, 2009; Toll \& Van Luit, 2013), a slower learning of the counting string (Noël, 2009), the use of less mature calculation strategies (Noël, Seron, \& Trovarelli, 2004) and lower accuracy in solving simple additions (Noël, 2009; Rasmussen \& Bisanz, 2005). Moreover, working memory capacities distinguish between typically developing children and children with math learning disabilities (Gathercole \& Pickering, 2000b; Toll, Van der Ven, Kroesbergen, \& Van Luit, 2011; Toll \& Van Luit, 2013).

The theoretical framework of most studies examining the relationship between working memory and mathematics is based on Baddeley and Hitch (1974)'s model. These authors defined working memory as a limited-capacity system, allowing the temporary storage and manipulation of information, and composed of one central executive (CE) and two slave systems, the phonological loop (PL) and the visuospatial sketchpad (VSSP). The slave systems are used for the temporary storage of verbal (PL) or visuospatial (VSSP) information and the CE is responsible for the trade-off between information storage and simultaneous processing. Hence, the PL and the VSSP are solicited in tasks requiring the temporary storage of verbal and visuospatial information, respectively, while the $\mathrm{CE}$ is involved in tasks requiring maintaining and manipulating verbal or visuospatial information. In 2000, Baddeley added a fourth component to his 
model: the episodic buffer. However, this has never been considered in numerical cognition studies and will thus not be further considered here. Based on this model, several authors have examined the specific relations of each working memory component with numerical development. Most studies with young children (5-7 years old) have shown a close relationship between the CE and mathematical performance assessed by a global counting (Kroesbergen et al., 2009) or math test (De Smedt, Janssen, et al., 2009). Regarding the slave systems, although there is no clear consensus, there seems to be a developmental shift from VSSP to PL use when performing numerical tasks; indeed, the VSSP seems to play a stronger role in young (preschool) children's math performance while older (primary school) children rely more on the PL (De Smedt, Janssen, et al., 2009; Holmes \& Adams, 2006; McKenzie et al., 2003; Raghubar et al., 2010; Rasmussen \& Bisanz, 2005; Titz \& Karbach, 2014; van der Ven, van der Maas, Straatemeier, \& Jansen, 2013).

If working memory is so important to building numerical processing, then intensive training of this process could indirectly increase mathematical abilities. Numerous authors have already examined the effectiveness of working memory training and several studies have yielded promising results with adults (Dahlin, Nyberg, Backman, \& Neely, 2008; Olesen, Westerberg, \& Klingberg, 2004; Westerberg \& Klingberg, 2007), adolescents and children (Alloway, Bibile, \& Lau, 2013; Dunning, Holmes, \& Gathercole, 2013; Gray et al., 2012; Holmes \& Gathercole, 2014; Holmes, Gathercole, \& Dunning, 2009; Karbach, Strobach, \& Schubert, 2015; Klingberg et al., 2005; Klingberg, Forssberg, \& Westerberg, 2002; Loosli, Buschkuehl, Perrig, \& Jaeggi, 2012; Van der Molen, Van Luit, Van der Molen, Klugkist, \& Jongmans, 2010) as well as with kindergarteners (Kroesbergen, Van't Noordende, \& Kolkman, 2014; Passolunghi \& Costa, 2014; Röthlisberger, Neuenschwander, Cimeli, Michel, \& Roebers, 2012; Thorell, Lindqvist, Bergman-Nutley, Bohlin, \& Klingberg, 2009).

In addition, a number of studies have tested the possible transfer effect of working memory training on numerical development (Bergman-Nutley \& Klingberg, 2014; K. I. E. Dahlin, 2013; Gray et al., 2012; Kroesbergen et al., 2014; Kyttälä, Kanerva, \& Kroesbergen, 2015; Passolunghi \& Costa, 2014). With children and adolescents, some studies showed a training-related effect on mathematics, measured by an academic test (Bergman-Nutley \& Klingberg, 2014; Holmes \& Gathercole, 2014) and on arithmetic (Witt, 2011). However, in other studies (Alloway et al., 2013; Dunning et al., 2013; Karbach et al., 2015; St Clair - Thompson, Stevens, Hunt, \& Bolder, 2010), improvement in working memory did not transfer to mathematics.

Several studies have been carried out with young children (5-8 years old). Two working memory training studies with kindergarteners (Kroesbergen et al., 2014; Passolunghi \& Costa, 2014) showed a positive impact on number skills. Indeed, playing games soliciting the $\mathrm{CE}$, during eight 30-minute sessions, yielded enhancement in the $\mathrm{CE}$ and in a dot comparison task; and when these games involved the storage and processing of numerical information, improvement was also observed in counting skills (assessed by the Early Numeracy Test-Revised, ENT-R; Van Luit \& Van de Rijt, 2008) (Kroesbergen et al., 2014). Similarly, Passolunghi and Costa (2014) observed an increase of performance in CE abilities as well as in early numeracy skills (measured with the ENT; Van Luit, Van de Rijt, \& Pennings, 1994) after ten 60-minute sessions of a working memory training program consisting of PL, VSSP and CE tasks. Finally, in St Clair Thompson et al. (2010)'s study, children, aged 5 to 8 years old, were trained with the Memory Booster program (Leedale, Singleton, \& Thomas, 2004) which aims to improve PL abilities by teaching three types of strategy (rehearsal, visual imagery and creating stories). Improved performance was observed in the PL, the CE, a following instruction task and mental arithmetic. However, other authors (Kanerva \& Kyttala, 2016; Kyttälä, Kanerva, \& Kroesbergen, 2015) did not observe any working-memory-training-related impact. Kyttälä et al. (2015) showed that eight 30-minute sessions of PL, VSSP and CE games with numerical materials did not enhance working memory and had no impact on early numeracy skills (assessed by the ENT-R; Van Luit \& Van de Rijt, 2008). In Kanerva and Kyttala (2016)'s study, specifically training the PL, the VSSP, the CE with verbal materials and the CE with visuospatial materials did not lead to improvement in any working memory component or in counting. In Honoré and Noël (in press), the Cogmed working memory training program (Klingberg et al., 2002) led to very specific effects on working memory (only the trained processes were improved) but almost no transfer to numerical and arithmetical skills. These weak effects are surprising considering the large number of studies showing a strong relation between working memory and numerical development (Bull, Espy, \& Wiebe, 2008; De Smedt et al., 2009; Gathercole, Brown, \& Pickering, 2003; Raghubar, Barnes, \& Hecht, 2010).

We can conclude that, to date, there is no consensus in the literature concerning the possibility of improving working memory abilities through training or concerning the possible transfer to numerical abilities, such as counting, magnitude comparison, number line positioning, and arithmetical skills.

In the present study, we developed a working memory training program and compared its effects to a control training condition (vocabulary learning) on kindergarteners' working memory as well as on numerical and arithmetical abilities. These skills were assessed just before, just after and 6 months after training. As numerical (e.g. De Smedt et al., 2009; Kroesbergen, Van Luit, Van Lieshout, Van Loosbroek, \& Van de Rijt, 2009) and arithmetical abilities (e.g. De Smedt et 
al., 2009; Gathercole \& Pickering, 2000a; Passolunghi \& Siegel, 2004) are more particularly related to the CE in young children (5-7 years old) and as working memory training in which strategies are taught seem effective in increasing CE performance (St Clair - Thompson et al., 2010), we developed a training program tapping the CE and used a visual-encoding-based strategy which was one of the strategies used by St Clair - Thompson et al. (2010). The rehearsal strategy and the creation of stories were not used as we consider them to be too difficult for young children (the children were a little older in St Clair - Thompson et al. (2010)'s study, i.e. 5 to 8 years old, compared to 5 to 6 years old in the present study).

We expected close-transfer effects with higher performance in CE tasks after training. Moreover, as the CE is responsible for the trade-off between information storage, supported by the slave systems, and simultaneous processing (Baddeley \& Hitch, 1974), tasks involving the CE should also solicit the slave systems, the PL and the VSSP. Accordingly, an effect is also expected in tasks tapping those slave systems. Regarding numerical development, training-related effects are expected if training is effective in enhancing working memory abilities. Indeed, as working memory abilities are important for learning mathematics (Jarvis \& Gathercole, 2003; McKenzie, Bull, \& Gray, 2003; Noël, 2009; Noël et al., 2004; Toll et al., 2011), higher working memory capacities should allow the learners to enter into learning more easily. Thus, we predicted an impact of training on counting, Arabic number comparison and calculation as number knowledge (Cohen Kadosh, Dowker, Heine, Kaufmann, \& Kucian, 2013; De Smedt et al., 2009) and arithmetic (Andersson, 2008; Andersson \& Lyxell, 2007; Barrouillet \& Lepine, 2005; Cohen Kadosh et al., 2013; De Smedt et al., 2009) have been shown to be related to CE capacities and two previous working memory training studies observed an improvement in early numeracy after training (Kroesbergen et al., 2014; Passolunghi \& Costa, 2014). In addition, collection comparison might be enhanced after training as Kroesbergen et al. (2014) observed higher performance in a dot collection comparison task after working memory training. Finally, we did not have a strong hypothesis concerning the impact of working memory training on number line positioning, but we might expect higher precision in a number-to-position task after training if participants did benefit from training to enter into numerical learning, leading to greater understanding of number magnitude.

We might possibly expect a different profile of effects on the numerical field according to the moment of observation. If higher training-related working memory capacities facilitate learning, then an immediate effect is expected to be observed in the numerical skills that are subject to learning during the training period, e.g. counting, magnitude understanding, visuospatial representations of numbers. In contrast, arithmetic is not explicity taught in kindergarten and formal learning of mathematics starts in primary school. Therefore, the experimental group should show higher performance than the control group in a calculation task 6 months later, when they have entered primary school and started to receive formal mathematical education.

\section{Method}

\subsection{Participants}

The participants were 34 children (mean age $=5$ years 7 months; $\mathrm{sd}=3.83$ months) recruited from a middle-social-class school in XXX. They were all native French speakers except for one child who was native Polish and spoke French fluently. Training took place at the end of the last year of kindergarten. Children were tested before training (T1), directly after (T2) and then 6 months after (T3) training. At T3, children had been in primary school for 2 months. The remaining sample for $\mathrm{T} 3$ consisted of 30 children (mean age $=5$ years 7 months; sd $=3.74$ months). Participants were randomly assigned to either the experimental $(\mathrm{N}=18)$ or the control $(\mathrm{N}=16)$ group.

\subsection{Procedure}

\subsubsection{Testing}

Thirteen tasks were used in T1, T2 and T3; six of them assessed the different components of working memory and seven assessed numerical development. The testing tasks were administered in two separate 40 -minute sessions. At post-test, the experimenter was blind to the condition the participant belonged to.

Working memory. The PL was measured with a forward word span. Children were told series of one-syllable words (Maillart, 2003), at the rate of one per second, and then asked to repeat them in the same order. The difficulty level started with series of two words and progressively increased by one word. Each length contained three series of words. If the child failed at two or three out of the three trials, the task stopped. A corrected span, corresponding to the longest length for which at least two trials were correctly repeated, plus .5 if one trial of the next series length was successful, was used as the dependent variable.

To assess the visuo-spatial sketchpad, we used the block tapping test (Corsi). In this task, nine identical cubes glued on a board (Farrell Pagulayan, Busch, Medina, Bartok, \& Krikorian, 2006) were placed between the experimenter and the child. The experimenter touched series of cubes of increasing length and the child had to point at the same cubes in the 
same order of presentation. Three trials per length were presented to the child and the task stopped when the child failed two or three trials. The corrected span was used as the dependent variable.

As the CE was the target process of the training program and any single measure includes error variance, multiple measures should be used to assess each construct (Hulme \& Melby-Lervag, 2012). Four tasks were used to evaluate this component. First, in the backward word span, the same materials and procedure as in the forward word span were used but children were asked to repeat the words in the reverse order. The dependent variable was the corrected span. Second, in the Odd One Out task, derived from the odd-man-out task (Russel, Jarrold, \& Henry, 1996), the child faced series of rectangles, arranged from left to right, containing three white squares on a computer screen, displayed using Power Point. When the child was attentive, the experimenter pressed the space bar and a circle appeared in each square of the first rectangle. Two circles were identical and the third one was different; the child was asked to point to the odd one out. Once the child had answered, the experimenter pressed the space bar once to make the circles disappear and then a second time to make the circles appear in the next rectangle. Once the child had pointed to the odd circle, the circles disappeared by pressing the spacebar. At the end of the trial, the child was asked to show the position of each odd circle. The same procedure and dependent variable as in the forward word span were used: there were three trials per length and a corrected span was calculated. Third, the categospan, developed by Noël (2009), is a categorization task in which one-syllable animals or food words were orally presented to the child, who had to repeat them by category, starting with the animals and ending with the food. During practice trials the items were presented both orally and visually. To help the child remember to recall one category and then the other, pictures of a forest (for the animals) and of a plate (for the food) were presented during all practice and test trials. Fourth, an updating task was developed, the musical chair task, in which children were presented with three chairs on a computer screen, using Power Point; the middle chair was brown while the two others were blue. The experimenter said "Animals are playing a sort of 'musical chairs'. Now you see three animals, each sitting on one chair, but they are going to move from their chair to the one on their left. So, this animal [pointing at the one on the left blue chair] is going to disappear, this one [pointing at the one on the middle brown chair] is going to this chair [pointing at the left blue chair], this one is going to this chair [pointing at the middle brown one] and another animal is coming from there [pointing at the right side of the screen] and going to this chair [pointing at the right blue chair]. You have to tap on the table each time the animals sitting on the blue chairs are identical". In other words, the child had to identify if the new animal (coming from the right side of the screen and going to the right blue chair) was the same as the $\mathrm{n}-2$ animal (situated on the left blue chair). There were five animals in total and the child was invited to name them before starting the task. During twelve practice trials, all animals were visible and there were two n-2 items (targets). The test trials were divided into two parts. In the first part, the animal sitting on the left blue chair was hidden behind a curtain and, in the second part, both the left and the middle animals were hidden behind the curtain. In each part, there were 6 targets (n-2), 6 near distractors (n-3) and 6 far distractors (n-8/9 for the first part and n-9/10 for the second part). Error rate and percentage of correct responses were recorded.

Numerical development. In the counting task, the child was asked to count out loud as high as he/she could and the highest number he/she produced in an errorless sequence was used as the dependent variable.

The elaboration of the counting string was assessed in a series of tasks, developed by Noël (2009), in which the child was asked to (a) count up to 6 and then up to 9, (b) count from 5 and then from 7 (the child was stopped when 10 was reached), (c) count from 5 to 9 and then from 4 to 8, (d) count two steps from 3 and then from 4 and (d) count three steps from 4 and then from 5. For these last two tasks, the experimenter explained the instructions as follows: "Imagine a frog jumping. If it jumps three times it does 'one - two - three' and if it jumps three times, starting at two, it does 'two - three-four'. Now it is your turn, the frog jumps two times starting at three, so it does ...?".

In the symbolic comparison task, the child was invited to select the larger of two Arabic numbers (from 1 to 19) presented simultaneously on a computer screen, using E-prime. Stimuli varied according to two numerical sizes, small (1-9) and large (10-19) and two numerical distances, close (1) and far (3), resulting in four conditions (far-small, close-small, far-large, close-large), containing each 6 different pairs, presented in two orders (ascending and descending) for a total of 48 items (6 pairs x 2 orders $\times 4$ conditions). All the stimuli were presented in a fixed random order, according to four criteria: maximum 3 consecutive same-answer items, maximum 2 consecutive same-condition items, no consecutive items of identical pair and the two first items corresponded to far-small pairs. The \% CR was used as the dependent variable.

The non-symbolic comparison task was an adaptation of Rousselle, Dembour, and Noël (2013)'s task. Children were presented with two boxes on a computer screen, using E-prime, each containing a collection of puzzle pieces and asked to select the larger collection. The amount of puzzle pieces varied from 5 to 18 , i.e. above the subitizing range. Six practice pairs of sets differing by a ratio of $1: 3$ familiarized children with the task. The test trials were pairs of sets differing by ratios of $1: 2,2: 3,3: 4,4: 5,5: 6,6: 7$ and 7:8. There were two pairs per ratio (7-14 and 8-16; 6-9 and 10-15; 6-8 and $12-16 ; 8-10$ and $12-15 ; 5-6$ and $10-12 ; 6-7$ and $12-14 ; 7-8$ and 14-16) and each pair was presented four times, 
varying along order (ascending or descending) and condition (congruent or incongruent), resulting in 64 items. Items were presented in a fixed random order, respecting five criteria: maximum 3 consecutive same-answer items, maximum 3 consecutive same-condition items, maximum 2 consecutive same-ratio items, no consecutive items of identical pair and the two first pairs were 1:2-ratio items. The $\% \mathrm{CR}$ was used as the dependent variable.

In the number line positioning task, children were invited to position an Arabic number on a horizontal non-graduated number line with 1 and 20 at the left and right sides. For each number to place (from 2 to 19), a new number line was presented. To measure the precision of the child's positioning on the number line, we calculated the median Percent Absolute Error $(\mathrm{PAE}=\mid[($ estimate - correct response $) /$ scale of estimate $] \mathrm{X} \mathrm{100} \mid)$ which was used as the dependent variable.

To assess arithmetic, two addition tasks were presented to children. First, we used a computerized task developed by Honoré and Noël (2016), the multiple-choice (MC) addition task. The screen was divided into two sections. The child was invited to first look at the left side of the screen displaying a box containing Easter eggs and an Arabic number. The experimenter said "You have [amount of Easter eggs] Easter eggs in your basket." while pointing at the Easter egg box, and "You find [Arabic number presented on the screen] more. How many do you have in total?". Then, the child was invited to look at the right side of the screen to give his/her answer. This side of the screen displayed the correct answer and the correct answer + or -1 , presented both in Arabic format and in collections of dots. In the second arithmetic task, developed by Noël (2009), the production addition task, children were invited to solve 10 additions $(4$ ties: $2+2,3+3,4+4$ and $5+5$ and six other problems: $2+3,2+4,2+5,3+4,3+5,4+5$ ). For each problem, the child was presented with a drawing of apples (corresponding to the first operand) and tokens were at his/her disposal. The experimenter said to the child "Here are [number of apples] apples. If you add [second operand] apples, how many would there be in total?”. The child's answer, use of drawing, tokens or fingers to count as well as the counting strategy (counting all, counting on and counting min) were recorded.

\subsubsection{Training}

The children were divided into eight groups of four or five children and took part in 16 20-minute training sessions, in a period of 8 weeks. During an additional session, training games and objectives were discussed. Four groups received the control training and four groups were engaged in the working memory training program. To maintain motivation throughout the whole training period, each group received a couple of puzzle pieces at the end of each session. They were invited to bring all their puzzle pieces to the last session to reconstitute the puzzle at the end of that session.

All children attended the 16 sessions and their motivation was easily maintained throughout the training period in both the training and the control groups.

Control training. Children were given story-based word-learning sessions. At each session, words were orally presented to children who were asked whether they knew these words or not; if they did, they were invited to explain them. They were told that they would hear these words in the story and that they had to detect them. Once they appeared in the story, they were discussed and a definition was given by the experimenter. At the end of the session, each child was asked to explain one of the words; if their answer was correct they were given a token and the children who had more tokens could choose the puzzle piece the group received (if some children were even, they chose together).

Working memory training. Each session consisted of one verbal game and one visuospatial game, selected from a set of games. All the games but one (Memory) requested the CE. The experimenter taught a visual-encoding-based strategy during all training games. Difficulty was increased throughout the training sessions by manipulating different parameters according to the task. When a child succeeded in a game, he/she received a token and, at the end of each session, the two children who had received the most tokens could choose one puzzle piece for their group.

Five different games were developed to train the CE in verbal working memory. Two updating games were developed: the Card game and the Question game. In the first game, a pile of cards, face down, was placed in the centre of a table and each child was invited to take a turn and draw a card. After the card was named, the experimenter guided the children for the encoding phase: "Thomas (name of the child) has picked a pig (item on the card). Everyone closes their eyes and takes a photograph of Thomas with the pig. Can everyone see Thomas in their head? Can you see his card? What is Thomas' card?". The second child drew a card and the experimenter guided the children in the encoding phase again. Then this child had to recall the previous child's card (n-1) to win a token. In the Question game, each child was asked a question, was invited to answer it and then had to answer the question of the $\mathrm{n}-1$ child. To increase difficulty across sessions, the distance between the child's card and the one to recall as well as the number of cards to recall increased: n-1;n-2;n-1 and $\mathrm{n}-2 ; \mathrm{n}-3 ; \mathrm{n}-1, \mathrm{n}-2$ and $\mathrm{n}-3 \ldots$ The three remaining games were categorization tasks. In the "I go to the Market" game, the children named an item they wanted to buy and then recalled all the items bought by the others plus their own according to the category they belonged to; for example, they were told to buy only food and clothes and to recall first all the food items and then all the clothes items. The Color Card game was similar to the Card game, except that cards had different color and the children were asked to recall cards according to the color. In the Cards-in-Pile game, the experimenter presented 
different cards, successively, then asked the children to name them and placed them in different piles. Then one child was randomly selected to recall all the cards of one of the pile. Difficulty was varied by adding categories, colors, piles or turns. The same encoding phase was presented by the experimenter in all tasks.

There were six visuospatial games. In the Grid game, which was an updating task, the children were presented with a grid on which they were asked to move a penguin. When a child took a turn, he had to move the penguin and recall its n-1 location. Difficulty increased by manipulating the distance (n-a) of the location to recall, the number of locations to recall and the size of the grid $(3 \times 3$ or $4 \times 4)$. Two categorization games were also developed: the Color Grid game and Nicolas' room. The first game was the same as the Grid game, except that the squares in the grid had different colors and the children had to recall the location of the penguin according to the color. Nicolas' room was a computerized game in which the children were told: "Nicolas is bored in his room, so he uses different objects: his toys, his clothes, his dad's tools, kitchen items... The objects he uses will appear successively and I would like you to name and remember their location". After all the items had been showed and disappeared, one randomly selected child was asked to recall the location of one category of objects. In these two categorization games, difficulty was adapted by manipulating the number of colors or categories and the number of locations to recall. In Memory, the children were presented with pairs of animal cards, face down, and had to turn one card then a second one and compare them. If they were identical, they could win the pair and play again; and if they were not, they had to turn them back. The Rabbit game was a computerized game in which the children saw a grid of colored circles. While a rabbit jumped from one circle to another, the children were asked to name the color of each circle and, once the rabbit had disappeared, one randomly child had to recall its different locations on the same grid, with gray instead of colored circles. Difficulty increased throughout the sessions by manipulating the number of jumps, the size of the grid $(3 \times 3$ and $4 \times 4)$ and by adding an interference task: asking the child to recall the color of one of the circles on which the rabbit had jumped. The last game was another computerized game, Mickey and Minnie Mouse, displaying a grid with Mickey Mouse at the upper left and Minnie Mouse at the bottom right. The experimenter told the children "Mickey Mouse would like to join Minnie but there are some traps on the path and he must avoid them. Look carefully and remember where the traps appear". The children were asked to name the different traps appearing successively on the grid and once they had seen all of them, the same grid as the one on the computer screen was presented on a sheet of paper. One randomly selected child was invited to move Mickey Mouse from his place to Minnie while avoiding the traps he/she saw on the computer. To increase difficulty, the number of traps and the size of the grid $(3 \times 4$ and $4 \times 5)$ were manipulated and an interference task was added (answering the question: "what trap appeared here [pointing at one location of the grid where a trap appeared]?"). The same encoding phase was presented by the experimenter in all tasks.

\section{Results}

\subsection{Group Comparison}

First of all, we compared both groups at T1 in terms of age and performance (see Table 1) in each testing task with one-way ANOVAs. The analysis revealed that both groups were equivalent in terms of age, $F(1,33)<1$, and all testing scores at $\mathrm{T} 1$ (Odd One Out: $F(1,33)=2.50, p=.124$; counting: $F(1,33)=2.76, p=.107$; collection comparison: $F(1,33)=$ $2.40, p=.131$; number line: $F(1,33)=1.18, p=.285$ and $F(1,33)<1$ for the other tasks).

Table 1. Age and performance in each testing task at T1, T2 and T3 for each group

\begin{tabular}{|c|c|c|c|c|c|c|}
\hline & \multicolumn{3}{|c|}{ Experimental group } & \multicolumn{3}{|l|}{ Control group } \\
\hline & T1 & $\mathrm{T} 2$ & T3 & $\mathrm{T} 1$ & $\mathrm{~T} 2$ & T3 \\
\hline Age & $67.43 \pm 3.47$ & & & $67.15 \pm 4.31$ & & \\
\hline Forward word span & $3.69 \pm 0.71$ & $3.36 \pm 0.51$ & $3.63 \pm 0.77$ & $3.81 \pm 0.98$ & $3.5 \pm 0.63$ & $3.6 \pm 0.63$ \\
\hline Corsi & $3.78 \pm 1.06$ & $3.72 \pm 0.75$ & $4.47 \pm 0.55$ & $3.59 \pm 0.71$ & $3.44 \pm 1.05$ & \\
\hline Backward word span & $2.22 \pm 0.65$ & $2.47 \pm 0.50$ & & $2.22 \pm 0.48$ & $2.25 \pm 0.55$ & $4.17 \pm 0.41$ \\
\hline Categospan & $2.89 \pm 0.58$ & $3.19 \pm 0.77$ & $3.73 \pm 0.53$ & $2.75 \pm 0.8$ & $3 \pm 0.80$ & $3.27 \pm 0.70$ \\
\hline Odd One Out & $2.86 \pm 0.82$ & $3.33 \pm 0.87$ & $3.97 \pm 0.81$ & $3.25 \pm 0.58$ & $3.13 \pm 0.70$ & $3.6 \pm 0.57$ \\
\hline Updating & $82.56 \pm 7.73$ & $88.43 \pm 9.49$ & $88.7 \pm 11.23$ & $81.25 \pm 5.02$ & $86.11 \pm 8.61$ & $86.59 \pm 6.63$ \\
\hline Counting & $30.83 \pm 14.85$ & $39.06 \pm 17.61$ & $44.6 \pm 18.87$ & $23.56 \pm 11.47$ & $33.5 \pm 16.59$ & $39.87 \pm 20.71$ \\
\hline $\begin{array}{l}\text { Elaboration of the } \\
\text { counting string }\end{array}$ & $32.22 \pm 19.96$ & $60.56 \pm 22.35$ & $80 \pm 21.08$ & $31.25 \pm 22.17$ & $53.13 \pm 26.76$ & $76.67 \pm 30.73$ \\
\hline Collection comparison & $66.07 \pm 7.12$ & $63 \pm 7.79$ & & $61.5 \pm 10.02$ & $63.17 \pm 5.45$ & \\
\hline $\begin{array}{l}\text { Arabic number } \\
\text { comparison }\end{array}$ & $79.28 \pm 18.14$ & $82.87 \pm 16.55$ & $96.25 \pm 3.54$ & $75 \pm 14.77$ & $79.56 \pm 17.43$ & $92.5 \pm 11.21$ \\
\hline Number line & $22.37 \pm 11.26$ & $16.88 \pm 10.14$ & $11.18 \pm 7.36$ & $18.43 \pm 9.67$ & $14.42 \pm 11.21$ & $11.28 \pm 5.16$ \\
\hline MC additions & $62.04 \pm 19.22$ & $64.81 \pm 19.92$ & & $58.85 \pm 17.34$ & $59.38 \pm 18.97$ & \\
\hline Production additions & $50 \pm 37.42$ & $60 \pm 32.36$ & $89.23 \pm 16.40$ & $42.50 \pm 37.68$ & $48.75 \pm 28.02$ & $85.65 \pm 16.67$ \\
\hline
\end{tabular}

Note. Measures are expressed in corrected span for forward/backward word spans, Corsi, Odd One Out and categospan; in percentage of correct responses for updating, elaboration of the counting string, collection/Arabic number 
comparison and both addition tasks; in highest number reached for counting; and in PAE for the number line.

\subsection{Correlations}

An Exploratory Factorial Analysis was computed in principal component analysis on the four CE tasks (backward word span, Odd One Out, Categospan and updating), then on the five numerical tasks (counting, elaboration of the counting string, collection comparison, Arabic number comparison and number line) and finally on the two arithmetical tasks (MC additions and Production additions) in order to compute one single factor for performance in CE, in numerical and in arithmetic (see table 2 for the loadings of each task into the factor and the percentage of explained variance). Then, we examined the relationships between the PL, the VSSP and the CE factor with the numerical factor and the arithmetical factor at $\mathrm{T} 1$ (see table 3). The analyses revealed a significant correlation between each slave system and the $\mathrm{CE}$ but no significant correlation between the two slave systems (PL and VSSP). Numerical and arithmetical abilities were positively related to each other. Finally and more importantly, the PL and the CE, but not the VSSP, correlated with numerical skills whereas the three working memory components positively correlated with arithmetic; the highest correlations concerning the association of numerical and arithmetical skills with the CE.

Table 2. Task loadings for the factors resulting from the factorial analysis on T1 scores

\begin{tabular}{ll}
\hline Task & Loading on the factor \\
\hline Factorial analysis for central executive & .590 \\
Backward word span & .736 \\
Odd One Out & .823 \\
Categospan & .605 \\
Updating & $\mathbf{4 8 . 3 4}$ \\
Percentage of explained variance & .781 \\
\hline Factorial analysis for numerical skills & .579 \\
Counting & .798 \\
Elaboration of the counting string & .589 \\
Collection comparison & -.646 \\
Arabic number comparison & $\mathbf{4 6 . 9 6}$ \\
Number line & .893 \\
Percentage of explained variance & .893 \\
\hline Factorial analysis for arithmetical skills & $\mathbf{7 9 . 7 9}$ \\
MC additions & \\
Production additions & \\
Percentage of explained variance &
\end{tabular}

Table 3. Correlations between working memory, numerical and arithmetical abilities at T1

\begin{tabular}{|c|c|c|c|c|}
\hline & 1. & 2. & 3. & 4. \\
\hline 1. PL & & & & \\
\hline 2. VSSP & .33 & & & \\
\hline 3. Central executive & $.57^{* *}$ & $.40^{*}$ & & \\
\hline 4. Numerical skills & $.40^{*}$ & .31 & $.46^{* *}$ & \\
\hline 5. Arithmetical skills & $.42^{*}$ & $.37^{*}$ & $.68^{* *}$ & $.68^{* *}$ \\
\hline
\end{tabular}

Note. ${ }^{* *} p<.01,{ }^{* *} p<.05$

\subsection{Training Effect}

To assess the immediate effect of training, we computed targeted multivariate analyses of variance (MANOVA) with Time (T1 and T2) as within-subject factor and Group (experimental and control) as a between-subject factor. The first one was conducted on working memory measures (forward word span, Corsi, backward word span, Categospan, Odd One Out and updating); the second one on numerical tasks (counting, elaboration of the counting string, collection comparison, Arabic number comparison, number line, multiple-choice additions and production additions). Univariate analyses were also conducted separately for each baseline task to check for any possible training effect. For these analyses, when the interaction between the time and the group was significant, we compared T1 and T2 performance for each group by computing contrasts with Bonferroni correction. Then, to assess the possible remaining effects 6 months later (T3), an ANCOVA was run on T3 scores with T1 scores as covariate and the group as factor.

\subsubsection{Immediate Training Effects on Working Memory}

The MANOVA indicated a significant effect of task, $F(5,160)=179.22, p<.001, \eta^{2}=0.848$, ; the highest performance was observed in forward word span (3.59 \pm 0.61$)$ and Corsi (3.64 \pm 0.79$)$, which did not statistically differ from each other $(p=1)$. Then, performances in Odd One Out $(3.14 \pm 0.67)$ and Categospan (2.96 \pm 0.65$)$, which were statistically equivalent $(p=1)$, were higher than in backward word span $(2.29 \pm 0.46, p<.001)$ which, in turn, was better performed than updating $(0.85 \pm 0.06, p<.001)$. The main effects of time, $F(1,32)=0.66, p=.424, \eta^{2}=0.020$, and group, $F(1,32)=$ $0.13, p=.721, \eta^{2}=0.004$, were non-significant. The Time $\mathrm{x}$ Group interaction effect was also non-significant, $F(5,160)=$ 
$1, p=.405, \eta^{2}=0.030$. As can be seen in table 4, the univariate tests of each verbal measure revealed a significant interaction effect in the Odd One Out task only. Contrast with Bonferroni corrections revealed that children from the experimental group increased their span from pre-test to post-test, $t(32)=3.32, p=.004, \eta^{2}=0.256$ whereas no significant change was noticed in the performance of the control group, $t(32)=0.64, p=1, \eta^{2}=0.013$.

So there was a slight training effect on the Odd One Out task only.

Table 4. Results of the ANOVAs testing for immediate training effects on each working memory baseline task $(F(1,32)$ value, $p$ value and effect size)

\begin{tabular}{llll}
\hline Task & Effect of time & Effect of group & Effect of interaction \\
\hline Forward word span & $6.89, p=.013, \eta^{2}=0.177$ & $0.16, p=.694, \eta^{2}=0.005$ & $0.30, p=.590, \eta^{2}=0.009$ \\
Corsi & $0.03, p=.862, \eta^{2}=0.001$ & $1.24, p=.275, \eta^{2}=0.037$ & $0.03, p=.862, \eta^{2}=0.001$ \\
Backward word span & $1.89, p=.179, \eta^{2}=0.056$ & $0.51, p=.482, \eta^{2}=0.016$ & $1.14, p=.293, \eta^{2}=0.034$ \\
Odd One Out & $3.28, p=.080, \eta^{2}=0.093$ & $0.51, p=.480, \eta^{2}=0.016$ & $7.52, p=.010, \eta^{2}=0.190$ \\
Categospan & $5.65, p=.024, \eta^{2}=0.150$ & $0.39, p=.539, \eta^{2}=0.012$ & $0.19, p=.668, \eta^{2}=0.006$ \\
Updating & $10.90, p=.002, \eta^{2}=0.254$ & $0.68, p=.414, \eta^{2}=0.021$ & $0.10, p=.760, \eta^{2}=0.003$ \\
\hline
\end{tabular}

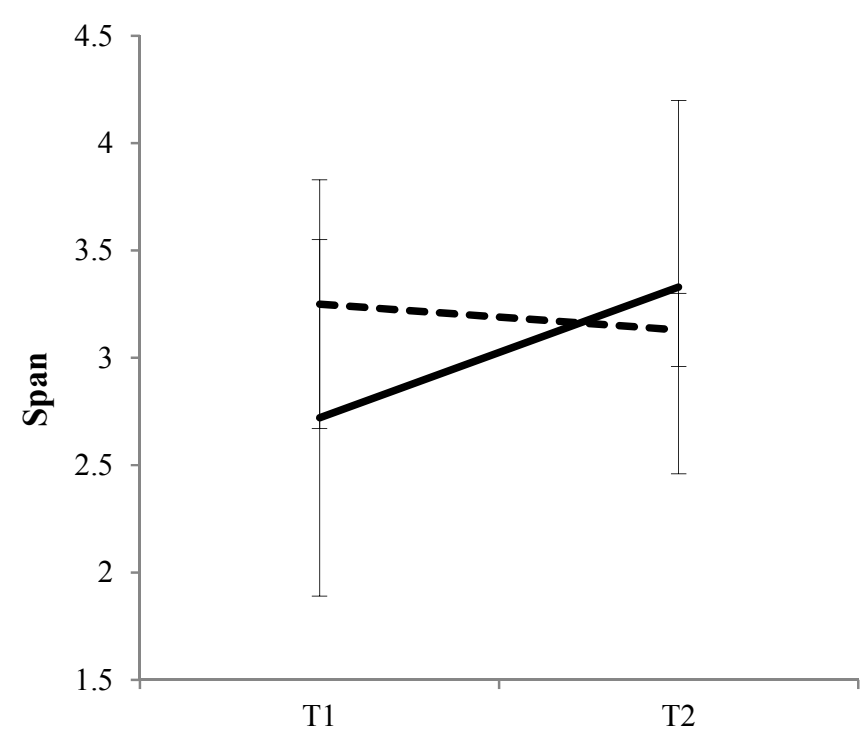

- Experimental group

Figure 1. Performance in terms of corrected span in the Odd One Out task in each group. Error bars represent standard errors

\subsubsection{Immediate Training Effects on Numerical Development}

The MANOVA indicated a significant effect of time $F(1,32)=40.39, p<.001, \eta^{2}=0.558$, and a non-significant effect of group, $F(1,32)=1.07, p=.310, \eta^{2}=0.032$. The effect of task was significant but it is not detailed here as the measures of each task were too different to be worth being compared (i.e. total success, \% CR, PAE). The Time $\mathrm{x}$ Group interaction effect was non-significant, $F(6,192)=0.45, p=.672, \eta^{2}=0.014$. The results of the repeated-measures univariate analysis of variance (table 5) showed no significant time $\mathrm{x}$ group interaction. See table 5 for statistics.

So, although children showed significant development of their numerical skills during this time period, there was no impact of working memory training on numerical abilities when measured just after the training period.

Table 5. Results of the ANOVAs testing for immediate training effects on each numerical baseline task(F $(1,32)$ value, $p$ value and effect size)

\begin{tabular}{lccc}
\hline \multicolumn{1}{c}{ Task } & Effect of time & Effect of group & Effect of interaction \\
\hline Counting & $20.53, p<.001, \eta^{2}=0.391$ & $1.74, p=.197, \eta^{2}=0.052$ & $0.18, p=.672, \eta^{2}=0.006$ \\
Elaboration of the counting string & $38.19, p<.001, \eta^{2}=0.544$ & $1.24, p=.275, \eta^{2}=0.037$ & $0.63, p=.433, \eta^{2}=0.019$ \\
Collection comparison & $0.18, p=.678, \eta^{2}=0.005$ & $1.13, p=.296, \eta^{2}=0.034$ & $2.02, p=.165, \eta^{2}=0.059$ \\
Arabic number comparison & $4.04, p=.053, \eta^{2}=0.112$ & $0.49, p=.488, \eta^{2}=0.015$ & $0.06, p=.813, \eta^{2}=0.002$ \\
Number line positioning & $4.68, p=.038, \eta^{2}=0.128$ & $1.21, p=.280, \eta^{2}=0.036$ & $0.11, p=.738, \eta^{2}=0.004$ \\
MC additions & $0.35, p=.558, \eta^{2}=0.011$ & $0.54, p=.469, \eta^{2}=0.017$ & $0.16, p=.688, \eta^{2}=0.005$ \\
Production additions & $5.12, p=.031, \eta^{2}=0.138$ & $0.70, p=.408, \eta^{2}=0.022$ & $0.27, p=.605, \eta^{2}=0.008$ \\
\hline
\end{tabular}




\subsubsection{Long-term Effects}

To assess long-term effects of the training, ANCOVAs were run on T3 scores with T1 scores as covariate and the group as factor. The analyses indicated a significant effect of group in the Categospan only, $F(1,27)=5.82, p=.023, \eta^{2}=0.177$ ( $F \mathrm{~s}<1$ for all tasks except for the Corsi, $F(1,27)=2.39, p=.134$ and the Odd One Out, $F(1,27)=2.63, p=.117$ ). Indeed, 6 months after the end of training, the experimental group outperformed the control group in the Categospan (See figure 2). For the numerical tasks however, none of the effects were significant.

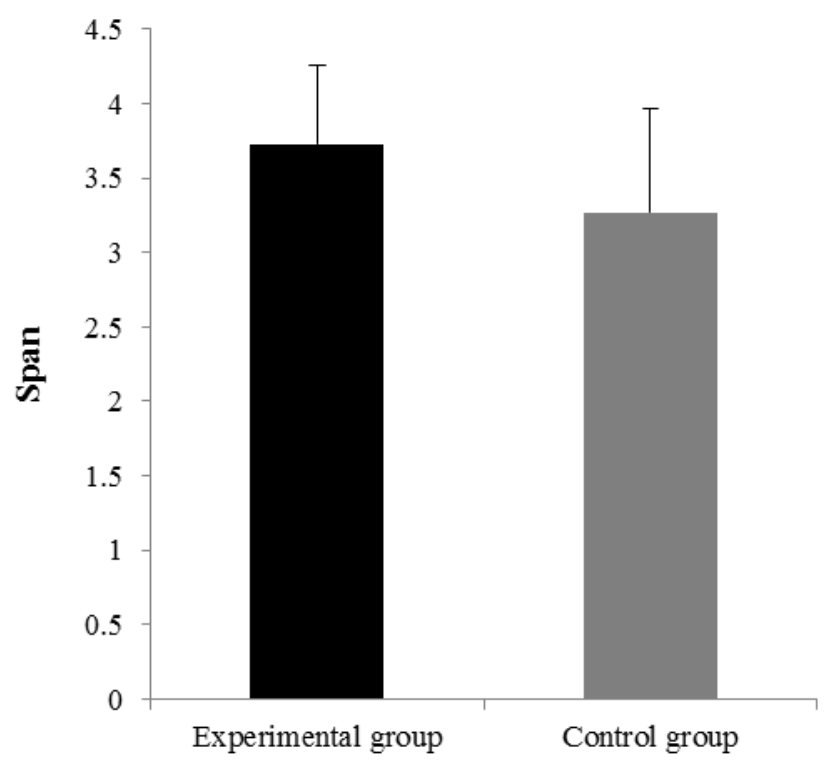

Figure 2. Scores in Categospan for each group at T3. Error bars represent standard errors.

\section{Discussion}

The present study aimed at better understanding the causal nature of the relation between working memory and numerical development by assessing the impact of a working memory training program tapping the $\mathrm{CE}$ on numerical and arithmetical skills and comparing it to a control-vocabulary-learning condition. As this is not the first study to address this question and there is no consensus in the literature regarding the effectiveness of such training, we developed a program based on the results of previous research so as to increase the effectiveness. First of all, participants were kindergarteners in an attempt to enrich this age-group literature, as only four studies have previously examined the impact of working memory training on numerical development with young children. We then developed several working memory tasks mainly tapping the CE because this working memory component has largely been associated with young children's arithmetical abilities (e.g. De Smedt et al., 2009; Gathercole \& Pickering, 2000a; Passolunghi \& Siegel, 2004). Moreover, working memory training tapping the CE has been shown to impact working memory and numerical skills with kindergarteners (Kroesbergen et al., 2014; Passolunghi \& Costa, 2014). Finally, training also aimed to teach a strategy as this is an efficient way in improving working memory abilities (St Clair Thompson et al., 2010); the strategy taught in our program was based on visual encoding, which is one of the strategies used in St Clair - Thompson et al. (2010)'s study. The impact of working memory training on working memory and numerical development was compared to an active cognitive training condition to control for spontaneous development. Participants were tested immediately after training as well as 6 months later to enable us to observe the indirect effects of increased working memory capacities on mathematical learning, once participants were in first grade.

First of all, we replicated the common findings in the literature showing a strong association between the CE and numerical (Kroesbergen et al., 2009; Noël, 2009; Passolunghi \& Lanfranchi, 2012) and arithmetical (Noël, 2009; Rasmussen \& Bisanz, 2005) performance in young children. As regards the slave systems, our results do not support the idea that young children rely more on the VSSP and less on the PL to perform numerical and arithmetical tasks (De Smedt et al., 2009; Holmes \& Adams, 2006; McKenzie et al., 2003; Rasmussen \& Bisanz, 2005). In contrast, they are in line with other studies which showed a significant correlation between PL abilities and arithmetic skills (Noël, 2009) and that PL capacities predicted arithmetic one and two years later (Attout et al., 2014). The stronger association between the $\mathrm{CE}$ and numerical and arithmetical skills reinforces the importance of using a training program focusing on the $\mathrm{CE}$ to impact arithmetic.

Immediately after training, a medium-effect-size impact was observed in one CE task but no effect was found on the 
slave system tasks. The immediate training effect on the CE task was not sustained 6 months later but a late medium effect appeared in another CE task. These effects are quite small; there was an impact in one out of the four CE tasks. However, it is important to note that the Odd One Out task is very different from all visuospatial tasks used in the training program. This is less the case for the Categospan task as this task is quite similar to the "I go to the market" training game. However, the effect observed in the Categospan task was observed 6 months after the end of the training and children probably did not have a clear memory of this game at the moment of testing.

The results are in line with the existing literature on kindergarteners; when an impact on working memory is observed, it is on CE skills, involving either verbal (Passolunghi \& Costa, 2014; Thorell et al., 2009) or visuospatial (Kroesbergen et al., 2014; Passolunghi \& Costa, 2014; Thorell et al., 2009) materials, with medium- (Kroesbergen et al., 2014) to large- (Passolunghi \& Costa, 2014; Thorell et al., 2009) effect sizes.

Regarding far-transfer effects, we did not observe any impact of training on numerical development either directly after training or 6 months later. In contrast, basic number skills were enhanced directly after training in Kroesbergen et al. (2014) and Passolunghi and Costa (2014)'s studies. However, it is important to note that several of the numerical abilities assessed in our testing were sensitive to change from T1 to T2 as the effect of time was significant for counting, elaboration of the counting string, number line positioning and production additions. Furthermore, numerical and arithmetical skills are supposed to significantly increase from $\mathrm{T} 2$ to $\mathrm{T} 3$ as participants go from kindergarten to first grade of primary school where formal mathematical education starts. So, despite the presence of significant performance increase of numerical and arithmetical skills, working memory training failed to impact this development.

Our training program thus led to higher performance in two CE tasks but failed to have any significant positive consequences on numerical and arithmetical skills. Up to now, evidence of far-transfer effect of working memory training on numerical abilities with kindergarteners has been controversial. Indeed, only two studies (Kroesbergen et al., 2014; Passolunghi \& Costa, 2014) have observed such an effect while two others have not (Kanerva \& Kyttala, 2016; Kyttälä et al., 2015). Kroesbergen et al. (2014) and Passolunghi and Costa (2014)'s training programs were similar to the present one in that they were non-computerized, implemented in small groups of children, tapped the CE with similar games and increased in difficulty with time. Moreover, our training included 16 sessions while the two other programs involved 8 (Kroesbergen et al., 2014) and 10 sessions only (Passolunghi \& Costa, 2014). Unlike ours, these studies observed a positive impact on numerical skills; i.e. on non-symbolic comparison after CE games (Kroesbergen et al., 2014) and on counting skills after PL, VSSP and CE games (Passolunghi \& Costa, 2014) as well as after CE games with numerical materials. Comparing the effects of the numerical working memory training program used in Kroesbergen et al. (2014)'s study to a counting training program, Kyttälä et al. (2015) did not find any positive effect of working memory training on counting skills. Finally, training one specific working memory component only (i.e. the PL, the VSSP, the CE with verbal materials and the CE with visuospatial materials) does not yield any gain in numerical development (Kanerva \& Kyttala, 2016). However, it is a little premature to come to a conclusion about the possibility or not of impacting numerical skills through working memory training as working memory abilities have not been improved (Kanerva \& Kyttala, 2016; Kyttälä et al., 2015), or have been slightly improved (Kroesbergen et al., 2014; Passolunghi \& Costa, 2014) in these studies. However, a change in the ability of interest should not depend on the type of task used. As performance in any single test relies on both the ability of interest and other random influences, training effects should be assessed and observed in multiple-task tests assessing the same latent variable (Shipstead, Redick, \& Engle, 2012). In contrast, in Passolunghi and Costa (2014)'s study, improvement was observed in the two tasks assessing the $\mathrm{CE}$ after training. So, although the training effect was observed on the working memory component which has the strongest associations with numerical development, i.e. the CE, in both studies, only Passolunghi and Costa (2014)'s results suggest that CE abilities did increase through training. Thus it is still not possible to know if increased working memory abilities through training impact the mathematical field as they may not have been deeply enhanced. There is, nevertheless, one study in which a positive working memory training effect was observed on working memory (PL and CE capacities) and mental arithmetic (St Clair - Thompson et al., 2010). However, the authors considered participants within a large age range (from 5 to 8 years old), mixing kindergarten and school-age children, who differ in terms of working memory abilities, capacity to understand the strategies taught, math skills, current learning... It is therefore not possible to know whether the kindergarteners alone would have similarly benefitted from training.

Future research should therefore focus on the possibility of improving young children's working memory abilities through training. Several meta-analyses suggest that the current training programs are not very efficient (Hulme \& Melby-Lervag, 2012; Melby-Lervag \& Hulme, 2013; Shipstead, Hicks, \& Engle, 2012; Shipstead, Redick, et al., 2012). Teaching various strategies might be considered. Indeed, it has been shown that working memory training in which three different strategies were taught, resulted in increased working memory (PL and CE) and mental arithmetic skills (St Clair - Thompson et al., 2010). It is possible that suggesting several strategies is more beneficial because children can choose to use the one that suits them best. 


\section{References}

Alloway, T. P., Bibile, V., \& Lau, G. (2013). Computerized working memory training: Can it lead to gains in cognitive skills in students? Computers in Human Behavior, 29(3), 632-638. https://doi.org/10.1016/j.chb.2012.10.023

Andersson, U. (2008). Working memory as a predictor of written arithmetical skills in children: The importance of central executive functions. British Journal of Educational Psychology, 78( $\mathrm{Pt} \quad 2)$, 181-203. https://doi.org/10.1348/000709907X209854

Andersson, U., \& Lyxell, B. (2007). Working memory deficit in children with mathematical difficulties: A general or specific deficit? Journal of Experimental Child Psychology, 96(3), 197-228. https://doi.org/10.1016/j.jecp.2006.10.001

Attout, L., Noël, M. P., \& Majerus, S. (2014). The relationship between working memory for serial order and numerical development: A longitudinal study. Developmental Psychology, 50(6), 1667-1679. https://doi.org/10.1037/a0036496.supp

Baddeley, A. D. (2000). The episodic buffer: A new component of working memory? Trends in Cognitive Sciences, 4(11), 417-423. https://doi.org/10.1016/S1364-6613(00)01538-2

Baddeley, A. D., \& Hitch, G. J. (1974). Working memory. In G. Bower (Ed.), The psychology of learning and motivation (Vol. 8, pp. 47-90). New York: Academic Press. https://doi.org/10.1016/s0079-7421(08)60452-1

Barrouillet, P., \& Lepine, R. (2005). Working memory and children's use of retrieval to solve addition problems. $J$ Exp Child Psychol, 91(3), 183-204. https://doi.org/10.1016/j.jecp.2005.03.002

Bergman-Nutley, S., \& Klingberg, T. (2014). Effect of working memory training on working memory, arithmetic and following instructions. Psychological Research, 78(6), 869-877. https://doi.org/10.1007/s00426-014-0614-0

Bull, R., \& Johnston, R. S. (1997). Children's arithmetical difficulties: Contributions from processing speed, item identification, and short-term memory. Journal of Experimental Child Psychology, 65, 1-24. https://doi.org/10.1006/jecp.1996.2358

Bull, R., Espy, K. A., \& Wiebe, S. A. (2008). Short-term memory, working memory, and executive functioning in preschoolers: Longitudinal predictors of mathematical achievement at age 7 years. Dev Neuropsychol, 33(3), 205-228. https://doi.org/10.1080/87565640801982312

Bull, R., Johnston, R. S., \& Roy, J. A. (1999). Exploring the roles of the visual - spatial sketch pad and central executive in children's arithmetical skills: Views from cognition and developmental neuropsychology. Developmental Neuropsychology, 15(3), 421-442. https://doi.org/10.1080/87565649909540759

Cohen Kadosh, R., Dowker, A., Heine, A., Kaufmann, L., \& Kucian, K. (2013). Interventions for improving numerical abilities: Present and future. Trends in Neuroscience and Education, 2(2), 85-93. https://doi.org/10.1016/j.tine.2013.04.001

Dahlin, E., Nyberg, L., Backman, L., \& Neely, A. S. (2008). Plasticity of executive functioning in young and older adults: Immediate training gains, transfer, and long-term maintenance. Psychology and Aging, 23(4), 720-730. https://doi.org/10.1037/a0014296

D'Amico, A., \& Passolunghi, M. C. (2009). Naming speed and effortful and automatic inhibition in children with arithmetic learning disabilities. Learning and Individual Differences, 19(2), 170-180.

https://doi.org/10.1016/j.lindif.2009.01.001

De Smedt, B., Janssen, R., Bouwens, K., Verschaffel, L., Boets, B., \& Ghesquiere, P. (2009). Working memory and individual differences in mathematics achievement: A longitudinal study from first grade to second grade. Journal of Experimental Child Psychology, 103(2), 186-201. https://doi.org/10.1016/j.jecp.2009.01.004

DeStefano, D., \& Lefevre, J. A. (2004). The role of working memory in mental arithmetic. European Journal of Cognitive Psychology, 16, 353-386. https://doi.org/10.1080/09541440244000328

Dunning, D. L., Holmes, J., \& Gathercole, S. E. (2013). Does working memory training lead to generalized improvements in children with low working memory? A randomized controlled trial. Developmental Science, 16(6), 915-925. https://doi.org/10.1111/desc. 12068

Espy, K. A., McDiarmid, M. M., Cwik, M. F., Stalets, M. M., Hamby, A., \& Senn, T. E. (2004). The contribution of executive functions to emergent mathematic skills in preschool children. Dev Neuropsychol, 26(1), 465-486. https://doi.org/10.1207/s15326942dn2601_6

Farrell Pagulayan, K., Busch, R. M., Medina, K. L., Bartok, J. A., \& Krikorian, R. (2006). Developmental normative 
data for the corsi block-tapping task. Journal of Clinical Experimental Neuropsychology, 28(6), 1043-1052. https://doi.org/10.1080/13803390500350977

Fuchs, L. S., Compton, D. L., Fuchs, D., Paulsen, K., Bryant, J. D., \& Hamlett, C. L. (2005). The prevention, identification, and cognitive determinant of math difficulty. Journal of Educational Psychology, 97(3), 493-513. https://doi.org/10.1037/0022-0663.97.3.493

Fuchs, L. S., Fuchs, D., Compton, D. L., Powell, S. R., Seethaler, P. M., Capizzi, A. M., ... Fletcher, J. M. (2006). The cognitive correlates of third-grade skill in arithmetic, algorithmic computation, and arithmetic word problems. Journal of Educational Psychology, 98(1), 29-43. https://doi.org/10.1037/0022-0663.98.1.29

Gathercole, S. E., \& Pickering, S. J. (2000a). Assessment of working memory in 6- and 7-year-old children. Journal of Educational Psychology, 92(2). https://doi.org/10.1037/0022-0663.92.2.377

Gathercole, S. E., \& Pickering, S. J. (2000b). Working memory deficits in children with low achievements in the national curriculum at 7 years of age. British Journal of Educational Psychology, 70, 177-194. https://doi.org/10.1348/000709900158047

Gathercole, S. E., Brown, L., \& Pickering, S. J. (2003). Working memory assessments at school entry as longitudinal predictors of national curriculum attainment levels. Educational and Child Psychology, 20(3), 109-122.

Geary, D. C., Hamson, C. O., \& Hoard, M. K. (2000). Numerical and arithmetical cognition: A longitudinal study of process and concept deficits in children with learning disability. $J$ Exp Child Psychol, 77(3), 236-263. https://doi.org/10.1006/jecp.2000.2561

Geary, D. C., Hoard, M. K., Byrd-Craven, J., Nugent, L., \& Numtee, C. (2007). Cognitive mechanisms underlying achievement deficits in children with mathematical learning disability. Child Dev, 78(4), 1343-1359. https://doi.org/10.1111/j.1467-8624.2007.01069.x

Gersten, R., Jordan, N. C., \& Flojo, J. R. (2005). Early identification and interventions for students with mathematics difficulties. Journal of Learning Disabilities, 38(4), 293-304. https://doi.org/10.1177/00222194050380040301

Gray, S. A., Chaban, P., Martinussen, R., Goldberg, R., Gotlieb, H., Kronitz, R., ... Tannock, R. (2012). Effects of a computerized working memory training program on working memory, attention, and academics in adolescents with severe ld and comorbid adhd: A randomized controlled trial. Journal of Child Psychology and Psychiatry, 53(12), 1277-1284. https://doi.org/10.1111/j.1469-7610.2012.02592.x

Hecht, S. A., Torgesen, J. K., Wagner, R. K., \& Rashotte, C. A. (2001). The relations between phonological processing abilities and emerging individual differences in mathematical computation skills: A longitudinal study from second to fifth grades. Journal of Experimental Child Psychology, 79(2), 192-227. https://doi.org/10.1006/jecp.2000.2586

Holmes, J., \& Adams, J. W. (2006). Working memory and children's mathematical skills: Implications for mathematical development and mathematics curricula. Educational Psychology, 26(3), 339-366. https://doi.org/10.1080/01443410500341056

Holmes, J., \& Gathercole, S. E. (2014). Taking working memory training from the laboratory into schools. Educational Psychology, 34(4), 440-450. https://doi.org/10.1080/01443410.2013.797338

Holmes, J., Gathercole, S. E., \& Dunning, D. L. (2009). Adaptive training leads to sustained enhancement of poor working memory in children. Developmental Science, 12(4), F9-15. https://doi.org/10.1111/j.1467-7687.2009.00848.x

Honoré, N., \& Noël, M. P. (2016). Improving preschoolers' arithmetic through number magnitude training: The impact of symbolic versus non-symbolic training. PLoS One, 11(11). https://doi.org/10.1371/journal.pone.0166685.g001

Honoré, N., \& Noël, M. P. (in press). Can working memory training improve preschoolers' numerical abilities. Journal of Numerical Cognition, 3(2).

Hulme, C., \& Melby-Lervag, M. (2012). Current evidence does not support the claims made for cogmed working memory training. Journal of Applied Resarch in Memory and Cognition, 1, 197-200. https://doi.org/10.1016/j.jarmac.2012.06.003

Jarvis, H. L., \& Gathercole, S. E. (2003). Verbal and non-verbal working memory and achievements on national curriculum tests at 11 and 14 years of age. Educational and Child Psychology, 20(3), 123-140.

Kanerva, K., \& Kyttala, M. (Eds.). (2016). Specific training of working memory and counting skills in kindergarten (Vol. 18). Copenhagen: Danish School of Education.

Karbach, J., Strobach, T., \& Schubert, T. (2015). Adaptive working-memory training benefits reading, but not 
mathematics in middle childhood. Child Neuropsychology, 21(3), 285-301. https://doi.org/10.1080/09297049.2014.899336

Klingberg, T., Fernell, E., Olesen, P., Johnson, M., Gustafsson, P., Dahlström, K., ... Westerberg, H. (2005). Computerized training of working memory in children with adhd - a randomized, controlled trial. Journal of the American Academy of Child and Adolescent Psychiatry, 44(2), 177-186. https://doi.org/10.1097/00004583-200502000-00010

Klingberg, T., Forssberg, H., \& Westerberg, H. (2002). Training of working memory in children with adhd. Journal of Clinical and Experimental Neuropsychology, 24(6), 781-791. https://doi.org/10.1076/jcen.24.6.781.8395

Kroesbergen, E. H., Van Luit, J. E. H., Van Lieshout, E. C. D. M., Van Loosbroek, E., \& Van de Rijt, B. A. M. (2009). Individual differences in early numeracy: The role of executive functions and subitizing. Journal of Psychoeducational Assessment, 27(3), 226-236. https://doi.org/10.1177/0734282908330586

Kroesbergen, E. H., Van't Noordende, J., \& Kolkman, M. (2014). Training working memory in kindergarten children: Effects on working memory and early numeracy. Child Neuropsychology: a journal on normal and abnormal development in childhood and adolescence, 20(1), 23-37. https://doi.org/10.1080/09297049.2012.736483

Kyttälä, M., Kanerva, K., \& Kroesbergen, E. (2015). Training counting skills and working memory in preschool Scandinavian journal of psychology. https://doi.org/10.1111/sjop.12221

Leedale, R., Singleton, C., \& Thomas, K. (2004). Memory booster (computer program and manual). Beverly, East Yorkshire: Lucid Research.

Loosli, S. V., Buschkuehl, M., Perrig, W. J., \& Jaeggi, S. M. (2012). Working memory training improves reading processes in typically developing children. Child Neuropsychology, 18(1), 62-78. https://doi.org/10.1080/09297049.2011.575772

McKenzie, B., Bull, R., \& Gray, C. (2003). The effects of phonological and visual-spatial interference on children's arithmetical performance. Educational and Child Psychology, 20(3), 93-108.

Melby-Lervag, M., \& Hulme, C. (2013). Is working memory training effective? A meta-analytic review. Developmental Psychology, 49(2), 270-291. https://doi.org/10.1037/a0028228

Noël, M. P. (2009). Counting on working memory when learning to count and to add: A preschool study. Developmental Psychology, 45(6), 1630-1643. https://doi.org/10.1037/a0016224

Noël, M. P., Seron, X., \& Trovarelli, F. (2004). Working memory as a predictor of addition skills and addition strategies in children. Current Psychology of Cognition, 22(1), 3-25.

Olesen, P. J., Westerberg, H., \& Klingberg, T. (2004). Increased prefrontal and parietal activity after training of working memory. Nature Neurosci, 7(1), 75-79. https://doi.org/10.1038/nn1165

Passolunghi, M. C., \& Costa, H. M. (2014). Working memory and early numeracy training in preschool children. Child Neuropsychology, 1-18. https://doi.org/10.1080/09297049.2014.971726

Passolunghi, M. C., \& Lanfranchi, S. (2012). Domain-specific and domain-general precursors of mathematical achievement: A longitudinal study from kindergarten to first grade. British Journal of Educational Psychology, 82(Pt 1), 42-63. https://doi.org/10.1111/j.2044-8279.2011.02039.x

Passolunghi, M. C., \& Siegel, L. S. (2004). Working memory and access to numerical information in children with disability in mathematics. J Exp Child Psychol, 88(4), 348-367. https://doi.org/10.1016/j.jecp.2004.04.002

Passolunghi, M. C., \& Siegel, L.S. (2001). Short-term memory, working memory, and inhibitory control in children with difficulties in arithmetic problem solving. J. Exp. Child Psychol., 80(1), 44-57. https://doi.org/10.1006/jecp.2000.2626

Passolunghi, M. C., Cornoldi, C., \& De Liberto, S. (1999). Working memory and intrusions of irrelevant information in a group of specific poor problem solvers. Memory and Cognition, 27(5), 779-790.

https://doi.org/10.3758/BF03198531

Passolunghi, M. C., Mammarella, I. C., \& Altoe, G. (2008). Cognitive abilities as precursors of the early acquisition of mathematical skills during first through second grades. Developmental Neuropsychology, 33(3), 229-250. https://doi.org/10.1080/87565640801982320

Passolunghi, M. C., Vercelloni, B., \& Schadee, H. (2007). The precursors of mathematics learning: Working memory, phonological ability and numerical competence. Cognitive Development, 22(2), 165-184.

https://doi.org/10.1016/j.cogdev.2006.09.001 
Raghubar, K. P., Barnes, M. A., \& Hecht, S. A. (2010). Working memory and mathematics: A review of developmental, individual difference, and cognitive approaches. Learning and Individual Differences, 20(2), 110-122. https://doi.org/10.1016/j.lindif.2009.10.005

Rasmussen, C., \& Bisanz, J. (2005). Representation and working memory in early arithmetic. Journal of Experimental Child Psychology, 91(2), 137-157. https://doi.org/10.1016/j.jecp.2005.01.004

Röthlisberger, M., Neuenschwander, R., Cimeli, P., Michel, E., \& Roebers, C. M. (2012). Improving executive functions in 5- and 6-year-olds: Evaluation of a small group intervention in prekindergarten and kindergarten children. Infant and Child Development, 21(4), 411-429. https://doi.org/10.1002/icd.752

Russel, J., Jarrold, C., \& Henry, L. (1996). Working memory in children with autism and with moderate learning difficulties. Journal of Child Psychology and Psychiatry, 37(6), 673-686. https://doi.org/10.1111/j.1469-7610.1996.tb01459.x

Shipstead, Z., Hicks, K. L., \& Engle, R. W. (2012). Cogmed working memory training: Does the evidence support the claims? Journal of Applied Research in Memory and Cognition, 1(3), 185-193. https://doi.org/10.1016/j.jarmac.2012.06.003

Shipstead, Z., Redick, T. S., \& Engle, R. W. (2012). Is working memory training effective? Psychological Bulletin, 138(4), 628-654. https://doi.org/10.1037/a0027473

St Clair-Thompson, H. L., \& Gathercole, S. E. (2006). Executive functions and achievements in school: Shifting, updating, inhibition, and working memory. Q J Exp Psychol (Hove), 59(4), 745-759. https://doi.org/10.1080/17470210500162854

St Clair-Thompson, H., Stevens, R., Hunt, A., \& Bolder, E. (2010). Improving children's working memory and classroom performance. Educational Psychology, 30(2), 203-219. https://doi.org/10.1080/01443410903509259

Thorell, L. B., Lindqvist, S., Bergman-Nutley, S., Bohlin, G., \& Klingberg, T. (2009). Training and transfer effects of executive functions in preschool children. Developmental Science, 12(1), 106-113. https://doi.org/10.1111/j.1467-7687.2008.00745.x

Toll, S. W. M., \& Van Luit, J. E. H. (2013). The development of early numeracy ability in kindergartners with limited working memory skills. Learning and Individual Differences, 25, 45-54. https://doi.org/10.1016/j.lindif.2013.03.006

Toll, S. W. M., Van der Ven, S.H., Kroesbergen, E. H., \& Van Luit, J. E. (2011). Executive functions as predictors of math learning disabilities. Journal of Learning Disabilities, 44(6), 521-532. https://doi.org/10.1177/0022219410387302

Van der Molen, M. J., Van Luit, J. E., Van der Molen, M. W., Klugkist, I., \& Jongmans, M. J. (2010). Effectiveness of a computerised working memory training in adolescents with mild to borderline intellectual disabilities. Journal of Intellectual Disability Research, 54(5), 433-447. https://doi.org/10.1111/j.1365-2788.2010.01285.x

Van Luit, J. E. H., \& Van de Rijt, B. A. M. (Eds.). (2008). Utrechtse getalbegrip toets-revised [Early Numeracy Test-Revised]. Doetinchem: Graviant.

Van Luit, J. E. H., Van de Rijt, B. A. M., \& Pennings, A. H. (Eds.). (1994). Utrechtse getalbegrip toets [Early Numeracy Test]. Doetinchem: Graviant.

Westerberg, H., \& Klingberg, T. (2007). Changes in cortical activity after training of working memory--a single-subject analysis. Physiology \& Behavior, 92(1-2), 186-192. https://doi.org/10.1016/j.physbeh.2007.05.041

Witt, M. (2011). School based working memory training: Preliminary finding of improvement in children's mathematical performance. Adv. Cogn. Psychol., 7, 7-15. https://doi.org/10.2478/v10053-008-0083-3

\section{Copyrights}

Copyright for this article is retained by the author(s), with first publication rights granted to the journal.

This is an open-access article distributed under the terms and conditions of the Creative Commons Attribution license which permits unrestricted use, distribution, and reproduction in any medium, provided the original work is properly cited. 